\title{
EVALUATION OF THE PLOTLESS SAMPLING METHOD TO ESTIMATE ABOVEGROUND BIOMASS AND OTHER STAND PARAMETERS IN TROPICAL RAIN FORESTS
}

\author{
KuMARATHUNGE, D.P. ${ }^{1,2} *$ - ThATTIL, R.O. ${ }^{2}$ - NisSANKA, S.P. ${ }^{2}$ \\ ${ }^{1}$ Institute of Fundamental Studies, Hantana Road, Kandy, Sri Lanka \\ (phone: 009481 2232002; fax: 009481 2232131) \\ ${ }^{2}$ Department of Crop Science, Faculty of Agriculture, University of Peradeniya, Sri Lanka \\ *Corresponding author \\ e-mail:dkumarathunge@gmail.com \\ (Received 22 ${ }^{\text {nd }}$ March 2010; accepted $26^{\text {th }}$ August 2011)
}

\begin{abstract}
Use of sampling techniques is of paramount importance since the precision of estimates greatly depend on it. Different methods of sampling have to be investigated to find out the best sampling technique for a given situation. This study was conducted to determine the best sampling technique to estimate tree diversity and aboveground biomass in Sinharaja forest. Three sampling techniques, namely; Quadrat method, Transect method, and Point centered quarter method (PCQ) were evaluated in this study. Sampling techniques were compared for tree density, basal area, aboveground biomass and diversity indices estimated by each technique. According to the results, PCQ method gave the highest precision for most of the parameters estimated. The non-linear functions fitted for the species - area (Quadrat method) and species - point (PCQ method) relationships estimated that the minimum total sampling area required to assess the number of tree species (in an area of $50 \mathrm{ha}$ ) of Singharaja forest as $6000 \mathrm{~m}^{2}$ for Quadrat method and 160 sampling points for PCQ method. It was difficult to estimate the minimum sampling area required to estimate the above ground biomass in Sinharaja since there was no clear cut relationship between biomass and number of sampling units. The results of the study emphasized that the PCQ method is a precise sampling technique that can be used to estimate the tree density, tree diversity and above ground biomass in natural forests. The random distribution of individuals is not necessary for tree diversity and biomass estimation by PCQ method if site stratification and random placement of sampling points in the study area are performed. Considering the higher precision of estimates and the saving of time and cost, the PCQ method can be recommended as an effective sampling technique for tree diversity and biomass studies.
\end{abstract}

Keywords: sampling techniques, point centered quarter method, rain forests, aboveground biomass, bio diversity

\section{Introduction}

Aboveground biomass is one of the "master variables" in determining especially the present status of, specially, the natural forests. Over the last few decades, estimation of aboveground biomass in natural forests as well as in plantations is made in the context of mitigating climate change. Carbon management in forests will be the single most important agenda of the first half of the $21^{\text {st }}$ century in most of the developed countries and some developing countries (Ramachandra et al., 2007). Under the United Nations Framework on Climate Change, countries have to report regularly the state of their forest resources and emerging mechanisms such as reducing emission from deforestation in developing countries (REDD) and they are likely to require temporally and specially fine-grained assessments of carbon stocks (UNFCCC, 2008). Therefore, estimation of aboveground biomass frequently in natural forests is of paramount importance. Studies have been carried out, following many sampling techniques such as 
random plots of various dimensions and sizes, viz. 100×100 m (Mani and Parthasarathy, 2007), 100 ha (Keller et al., 2001), 20×20 m (Ramachandra et al., 2007). Although these studies contributed to the knowledge of aboveground biomass in tropics, it is uncertain whether the sampling technique adapted in these studies truly represents the aboveground biomass or not. Secondly, in the discussion part of many of the above studies, the results are compared with those of similar studies conducted elsewhere, to rank the aboveground biomass as equal, higher or lower. We presume that these kinds of comparisons may not be rational and may give a false impression about the aboveground biomass of a forest or a region. Estimation of aboveground measures will depend on the sampling methods used. Permanent sampling plots (Alder and Synot, 1992) have been used for biomass inventories but establishment and maintenance of these plots is costly and time consuming. Due to high natural variability in tropical forests especially in terms of topography, species diversity etc. a few permanent or temporary sampling plots do not give a clear picture of the aboveground biomass. There is no clear-cut method available to determine the optimum plot size (which is a key variable that affects the accuracy of the estimates) required for biomass studies. Many scientists have been working on area independent sampling techniques as a solution to the disadvantages of area dependent methods i.e. plot based methods, but no information is found on the applicability of those techniques in the area of biomass studies. In this paper the applicability of an area independent sampling technique i.e. point centered quarter (pcq) method (Krebs, 1989) in biomass studies will be evaluated with comparison to the other conventional techniques.

\section{Materials and methods}

\section{Research site}

This study was carried out in the Singharaja forest located in the low country wet zone of Sri Lanka. $\left(6^{\circ} 25^{\prime} 00^{\prime \prime} \mathrm{N}, 80^{\circ} 30^{\prime} 00^{\prime \prime} \mathrm{E}\right)$. The entire area receives more than 2500 $\mathrm{mm}$ of rainfall annually with no long dry spells. Up to $900 \mathrm{~m}$ from the mean sea level, the vegetation is classified as tropical wet evergreen forest and above $900 \mathrm{~m}$ as sub montane evergreen forest (Gunatilleke et al., 2004).

\section{Site stratification}

The Landsat ETM+ image of the Sinharaja forest acquired in year 2005 was used for site stratification. The image was subjected to unsupervised classification using the Erdas Imagine 8.6 software. After classification, five different classes were identified based on the reflectance from different vegetation types. An area about 50ha that represents all the five classes was selected as the study area. Latitude and longitude was noted for each stratum for identification of these different vegetations inside the forest.

\section{Evaluation of sampling techniques}

In this study, the PCQ method was compared with two other conventional sampling techniques namely; Quadrat method and Transect method. Here, the quadrat method is considered as the standard sampling method and other two were compared as substitute techniques for the quadrat method. Initially, the stratified image of the study area was divided in to $50 \mathrm{~m}$ grids and a random value of latitude and longitude was selected for each grid. This random point was considered as the sampling points for the PCQ 
method. The pre determined sampling points were located in the field with the hand held Global Positioning System (GPS) which has an accuracy of less than $5 \mathrm{~m}$. at each sampling point. The area around was divided in to four quadrants (Fig. 1). The nearest tree to the sampling point which had more than $5 \mathrm{~cm}$ diameter at 1.3 above the tree base $(\mathrm{DBH})$ in each quadrant was selected for sampling and, therefore, four trees were included in the sample at each selected sampling point. The distance from the point to each selected tree was measured and in each selected tree, the DBH and tree height were measured using DBH tape and Clinometer. Species name of the trees was also recorded. This method was continued for a total of 120 sampling points.

For the quadrat method, $25,15 \times 15 \mathrm{~m}$ temporary sampling plots were used to sample vegetation. The plots were demarcated using a rope and a hand held compass. Plots were distributed in each stratum in such a way that each stratum contained at least five plots. The slope of the plots was recorded for slope correction. All trees having DBH greater than $5 \mathrm{~cm}$ within each quadrat were sampled for their $\mathrm{DBH}$, height and species level. For the transect method, eleven, $5 \times 100$ transects were used for sampling. The sampling procedure was the same as for the quadrat method.

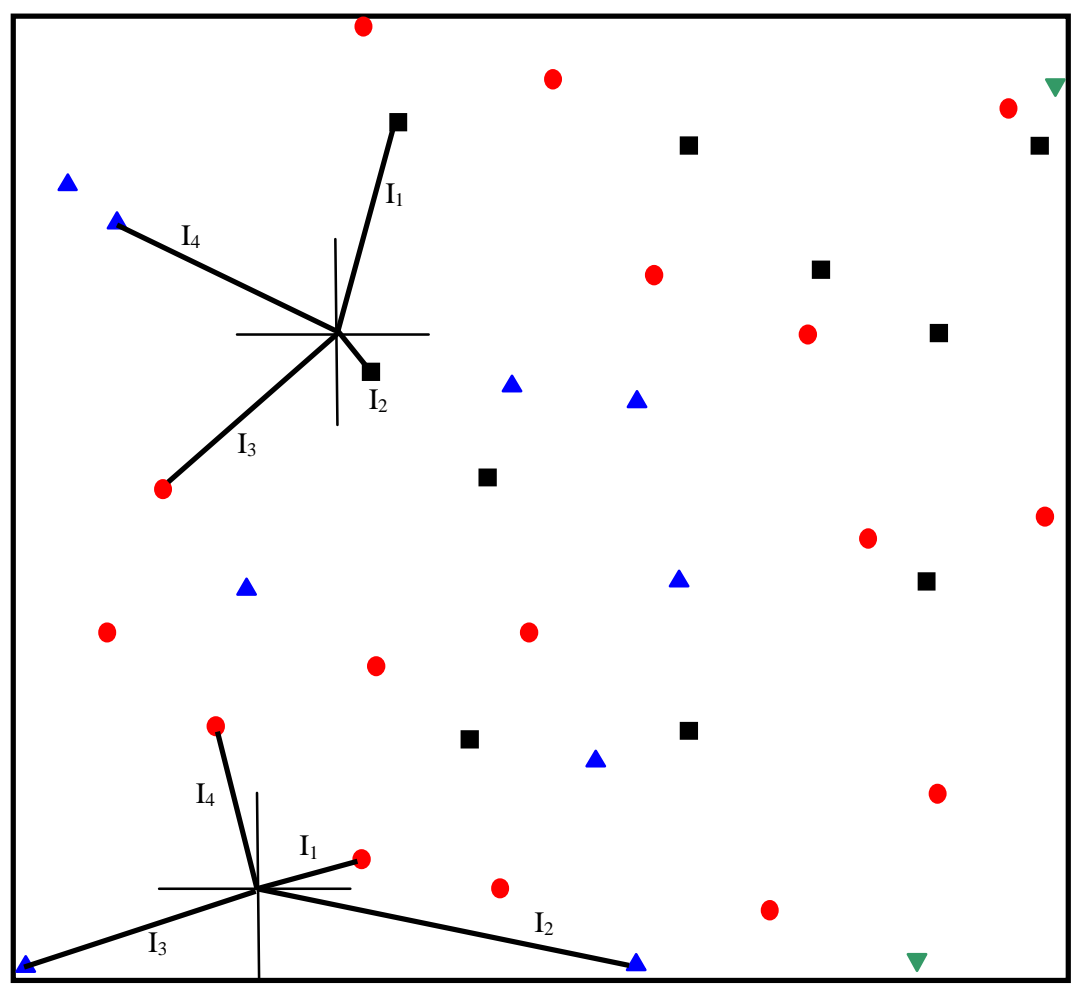

Figure 1. The point centered quarter method. The + represents the random point, around which four quadrants are established, and the distance to the nearest tree, $I_{i}$ is measured in each quadrant. The symbols $\bullet \nabla \square$ - represent four different tree species.

Since three sampling techniques are different from each other, it is impossible to allocate equal conditions (i.e. size of a single sampling unit) for each method. To overcome this, pre determined, total sampling area was selected as 50 ha and the interesting parameters of this area were evaluated using three different sampling techniques. Therefore, for comparison, size of a single sampling unit in each technique might not necessarily be the same since all techniques estimates the interesting 
parameters in a same area. But, the total sampling area of quadrat and transect methods were kept equal as much as possible.

\section{Estimation of aboveground biomass}

Here we used a general model to calculate the aboveground biomass. This model assumes a universal form factor for all tree species, which is considered as 0.7 (Browns, 1989). Biomass is calculated using the following formula.

$$
\text { Biomass }=h \times\left(\frac{\pi\left(D B H^{2}\right)}{4}\right) \times f \times \rho
$$

Where $\mathrm{h}=$ stem height $(\mathrm{m}), f=$ form factor and $\rho=$ wood specific gravity $\left(\mathrm{kg} / \mathrm{m}^{3}\right)$. Since the general way of estimating the biomass density (biomass per ha) cannot be applied to the PCQ method, a formula was derived considering the maximum area belonging to a particular sampling point. The formula is

$$
\text { Biomass density }(\mathrm{kg} / \mathrm{ha})=\frac{B_{i}}{\pi r_{\max }} \times 10^{4}
$$

Where $\mathrm{B}_{i}=$ total aboveground biomass of $i^{\text {th }}$ sampling point, $r_{\max }=$ maximum length measured in $i^{\text {th }}$ sampling point and $\pi=3.14159$.

Apart from the aboveground biomass, the tree sampling techniques were compared for other forest stand parameters such as absolute tree density, basal area and diversity indices. The widely used Shannon-Wiener diversity index was calculated according to Magurran (1988).

$$
H=-\sum p_{i} \ln p_{i}
$$

Where $H=$ species abundance, $p_{i}=$ proportion of individuals

The nonlinear regression procedure in Statistical Analysis System (SAS, 2000) was used to model the aboveground biomass and other interesting parameters with the size of the sampling units (for both PCQ and quadrat methods). Several non-linear models were fitted for the above relationships to find out the best-fitted model. Parameter estimation for each model was done using the PROC MODEL and PROC NLIN procedures in SAS.

\section{Results and discussion}

The total number of tree species recorded by the quadrat, Transect and PCQ methods was 107,103 and 87 respectively. The highest number of species per 100 individuals $(18.12 \%)$ was recorded by the PCQ method. The mean tree density estimated by quadrat and Transect methods was not significantly different (Table 1). But the PCQ method was the most precise technique to estimate the tree density since the standard error of estimate was very small compared to the other methods. 
Table 1. Estimated forest parameters by three different sampling techniques (values in parentheses are standard errors of estimates)

\begin{tabular}{c|c|c|c|c}
\hline $\begin{array}{c}\text { Sampling } \\
\text { technique }\end{array}$ & $\begin{array}{c}\text { Species } \\
\text { percentage }\end{array}$ & $\begin{array}{c}\text { Tree density } \\
\left.\text { (trees ha- }^{-1}\right)\end{array}$ & $\begin{array}{c}\text { Basal area } \\
\left(\mathbf{m}^{\mathbf{2}} \mathbf{h a}^{-\mathbf{1}}\right)\end{array}$ & $\begin{array}{c}\text { Diversity index } \\
\left(\text { Shannon- }^{\text {Wiener index })}\right.\end{array}$ \\
\hline Quadrat & $10.84 \%$ & $1712(81.5)$ & $42.5(2.62)$ & $3.86(0.008)$ \\
Transect & $18.12 \%$ & $1710(74.8)$ & $39.5(4.32)$ & $3.91(0.016)$ \\
PCQ & $17.19 \%$ & $1632(3.40)$ & $42.5(4.72)$ & $3.72(0.0036)$ \\
\hline
\end{tabular}

Based on the standard error (SE) of estimate quadrat method is the most precise technique to estimate basal area. But the SE of PCQ method is not very different. So both these estimates can be considered as precise estimates.

\section{Aboveground biomass}

The average aboveground biomass density of the study area in terms of the different sampling techniques is given in Table 2. The results emphasizes that, the PCQ technique is the most precise sampling technique to estimate aboveground biomass in the study area. Considering the basic principles, sampling units of the PCQ technique can be distributed throughout the study area with low cost and time compared to the quadrat method. One of the limitations of quadrat sampling is that when the size of the quadrat increases, the cost associated with including one additional plot is much higher. So in most of the situations, the number of sampling units that can be accommodated in the study may not be enough to represent the spatial variability of the aboveground biomass in the study area. The PCQ method can easily overcome this, since there is no limiting to increase the number of sampling units. And this technique is an important technique to determine the spatial variability of aboveground biomass since it allows more sampling units that can cover a large area. Quadrat method is not a good technique in such a situation because it is impossible to have large number of plots to represent the spatial variability accurately. Other than that, when taking measurements from large number of trees, the error associated with measurements increase. In PCQ method, only four trees are sampled per sampling point thus the total number of trees to be sampled is lower than other conventional techniques.

Table 2. Estimated aboveground biomass and their standard errors

\begin{tabular}{c|c|c}
\hline Sampling technique & Biomass (Mt ha-1) & Standard error \\
\hline Quadrat & 358.9 & 46.9 \\
Transect & 394.5 & 56.1 \\
PCQ & 339.4 & 38.8 \\
\hline
\end{tabular}

The PCQ method can be precisely used to model the relationship between number of sampling units and number of tree species in the study area (Fig. 2a). The best-fitted model was

$Y=106.06-96.63 e^{0.015 P}\left(\mathrm{R}^{2}=0.98\right)$ where $\mathrm{Y}$ is the expected number of species and $\mathrm{P}$ is no of points requited. According to this model the minimum number of sampling points required to assess the number of tree species in an area of 50 ha is 160 . The same procedure was followed to model the species-area relationship (for quadrat method) and the best-fitted model was 
$Y=124.608-131.2678 e^{-0.0052 A}\left(\mathrm{R}^{2}=0.99\right)$ where $\mathrm{Y}$ is the expected number of species and $\mathrm{A}$ is the area. According to the derived curve, it is clear that the number of species do not show a significant increment after $6000 \mathrm{~m}^{2}$. After this point, the increment of number of species is declining and it is around 0.1 species per $100 \mathrm{~m}^{2}$. Therefore $6000 \mathrm{~m}^{2}$ will be the minimum and economical sampling area required to assess the number of tree species in the study area, using the quadrat method. These estimates can be recommended for biomass studies as well because the inclusion of practically all the tree species in 50 ha of the study area is assured. When the total study area is larger than 50 ha, the number of sampling units should increase proportionately.

It was difficult to estimate the minimum sampling area required to estimate aboveground biomass in Sinharaja by all three methods. However with the PCQ method there was an indication that around 70 sampling points was adequate to estimate the aboveground biomass.

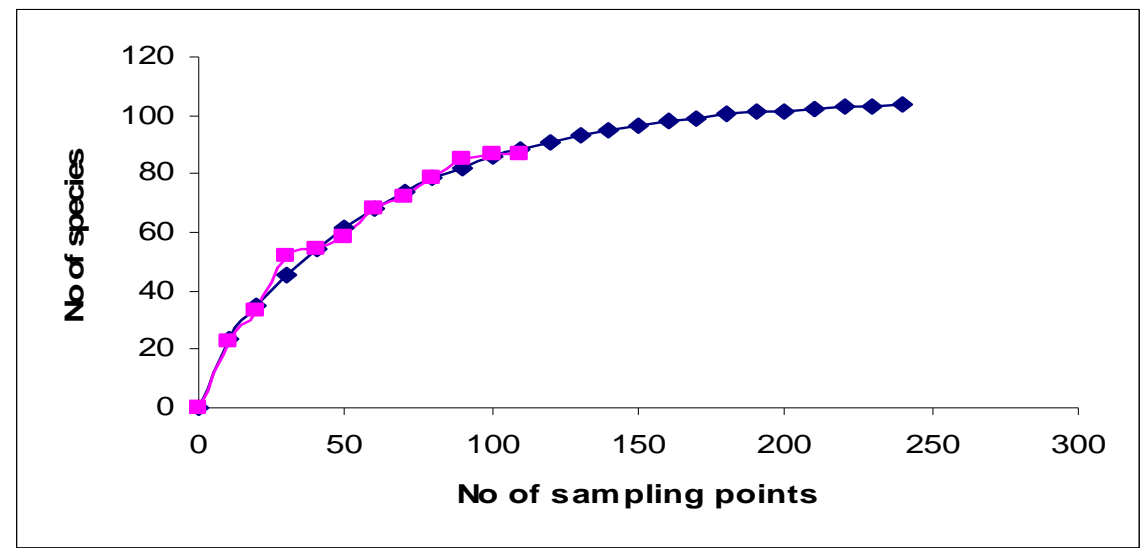

Figure 2. a Derived species - point curve for the study area. The fitted curve reaches a plateau at about 160 sampling points which is the minimum number of sampling points required for the $P C Q$ method to estimate the tree diversity of the study area

$\square=$ Expected no of species, $\quad \square=$ Observed no of species

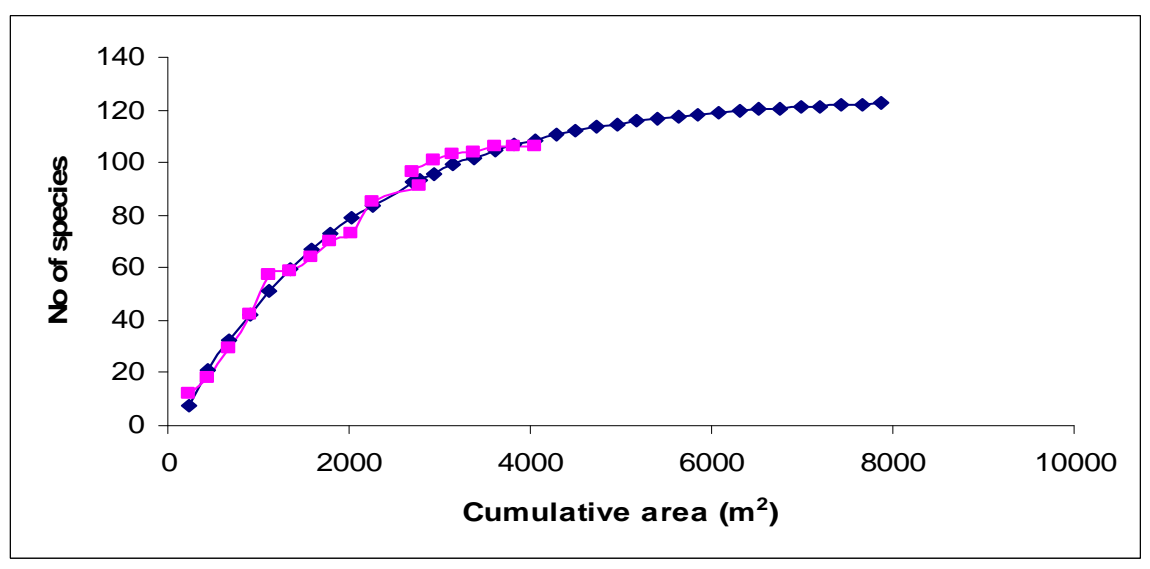

Figure 2. $\boldsymbol{b}$ Derived species - area curve for the study area. The fitted curve reaches a plateau at about $6000 \mathrm{~m}^{2}$ which is the minimum sampling area required for the quadrat method to estimate the tree diversity of the study area. $\mathbf{\square}=$ Expected no of species, $\square=$ Observed no of species 


\section{Sampling efficiency}

In this study, the average number of sampling points (in PCQ method) per man day is inbetween 15-20, under clear weather. For quadrat method and transect method the average number of plots per man-day is 3 and 2 respectively. So it is clear that, PCQ method is both a cost and time saving sampling method, compared to other conventional sampling techniques. Spatial variability can be easily handled by this method because the researcher can allocate more and more sampling units if necessary without much increase in cost and time.

\section{Conclusion}

Considering the higher precision of estimates and the saving of time and cost, the PCQ method can be recommended as an effective sampling technique for aboveground biomass studies in tropical wet evergreen forests. The present study stimulates certain issues worth considering in future studies: (a) experimental designs to estimate the minimum sampling area required to estimate the aboveground biomass and (b) validation of these results for other forest types in the tropics.

Acknowledgements. Authors wish to thank Conservator General of forests, Department of forestry, Battaramulla for giving the permission to carry out this study in Sinharaja forest. Mr. R.H.G Ranil and Mr.P.S.Pathinayake, Department of Crop Science, Faculty of Agriculture, University of Peradeniya are also acknowledged for the valuable support given throughout the study.

\section{REFERENCES}

[1] Alder, D., Synnott, T.J. (1992): Permanent sample plot techniques for mixed tropical forests. Tropical forestry papers (25) - Oxford forestry institute, University of Oxford.

[2] Browns, S. Gillespie, A.J.R. Lugo, A.E. (1989): Biomass estimation methods for tropical forests with application to the forest inventory data. - Forest Science. 35(4): 881-902.

[3] Gunatilleke, C.V.S., Gunatilleke, I.A.U.N., Ethugala, A.U.K., Esufali, S. (2004): Ecology of Sinharaja forest and the Forest Dynamics Plot. - WHT publication Ltd, Colombo, Sri Lanka.

[4] Keller, M., Palace, M., Hurtt, G. (2001): Biomass estimation in the Topajos national forest, Brazil. Estimation of sampling and allometric uncertainties. - Forest Ecology and Management 154: 371-382.

[5] Krebs, C.J. (1999): Ecological Methodology. - Second edition. Addison-Welsey, Canada.

[6] Magurran, A.E. (1987): Ecological Diversity and its Measurement. - Champan and Hall Limited, London.

[7] Mani, S., Parthasarathy, N. (2007): Above-ground biomass estimation in ten tropical dry evergreen forest sites of peninsular India. - Biomass and Bioenergy 31: 284-290.

[8] Ramachandran, A., Jayakumar, S., Haroon, R.M., Bhaskaran, A., Arockiasami, D.I. (2007): Carbon sequestration: estimation of carbon stocks in natural forests using geospatial technology in the Eastern Ghats of Tamil Nadu, India. - Current Science 92(3).

[9] SAS Version 8(2000): SAS Institute Inc. Cary, NC, USA.

[10] UNFCCC (United Nations Framework Convention on Climate Change) (2008): Report of the conference of the parties on its thirteen session. - Bali, 3-15 December 2007. Addendum, part 2. Document FCCC/CP/2007/6 Add.1. UNFCCC. Bonn, Germany. 